\title{
Cation Disorder Caused by Olivine-Ringwoodite Phase Transition Mechanism, Possible Explanation for Blue Olivine Inclusion in a Diamond
}

\author{
William A. Bassett ${ }^{1, *}$ and Elise A. Skalwold ${ }^{2}$ \\ 1 Earth and Atmospheric Sciences, Cornell University, Ithaca, NY 14850, USA \\ 2 Cornell University, Ithaca, NY 14850, USA; elise@nordskip.com \\ * Correspondence: wab7@cornell.edu; Tel.: +607-351-0604
}

Citation: Bassett, W.A.; Skalwold,

E.A. Cation Disorder Caused by

Olivine-Ringwoodite Phase

Transition Mechanism, Possible

Explanation for Blue Olivine

Inclusion in a Diamond. Minerals

2021, 11, 202. https://doi.org/

$10.3390 / \min 11020202$

Academic Editor: Martin Kunz

Received: 31 December 2020

Accepted: 12 February 2021

Published: 15 February 2021

Publisher's Note: MDPI stays neutral with regard to jurisdictional claims in published maps and institutional affiliations.

Copyright: () 2021 by the authors. Licensee MDPI, Basel, Switzerland. This article is an open access article distributed under the terms and conditions of the Creative Commons Attribution (CC BY) license (https:// creativecommons.org/licenses/by/ $4.0 /)$.

\begin{abstract}
Synchrotron X-ray diffraction, as well as visual observations, in a diamond anvil cell (DAC) using soft metal gaskets or slightly reducing gas environment, have revealed that the olivineringwoodite transition in olivines of several compositions take place in two steps: step 1: displacive restacking of the oxygen layers, followed by step 2: diffusive reordering of the cations. The initiation of the phase transition was observed at temperatures as low as $200{ }^{\circ} \mathrm{C}$ below the reported temperature for the phase transition under hydrostatic conditions. These observations, especially residual disordered cations, have important implications for deep-focus earthquakes, the ability of ringwoodite to host surprising amounts of water, and possibly the observation of a blue olivine inclusion in a natural diamond from Brazil and in a pallasitic meteorite from Russia.
\end{abstract}

Keywords: mantle; olivine; ringwoodite; wadsleyite; high pressure-temperature; shear deformation; diamond anvil cell; synchrotron radiation

\section{Introduction}

A review of past research offers a new perspective on that of the present and a possible guidance for future investigations. In 1979, one of us, Bill Bassett, attended a conference in Canberra, Australia. He was especially intrigued by a paper on the martensitic nature of the olivine-ringwoodite phase transition presented by Jean Paul Poirier of the University of Paris [1]. That paper inspired him to pursue the subject of olivine-spinel transition using the newly constructed Cornell High Energy Synchrotron Source (CHESS). In 1981, Bill and his students were just learning of the extraordinary opportunities offered by the small, intense X-ray beams available at CHESS for research on the properties of minerals at high pressures and temperatures in a diamond anvil cell (DAC). His student, Michael Furnish, and he [2] designed a geared-down system for remotely increasing pressure at high temperature, $520^{\circ} \mathrm{C}$, and in the presence of shear stress, so they would be able to watch changes in X-ray diffraction patterns in real time [2]. Decades later, Bill learned of the interests that another Cornellian, Elise Skalwold, had in minerals and gems, as well as the advanced methods for studying them. She brought along new ideas and eventually rekindled her co-author's fascination with the extraordinary nature of the olivine transition to ringwoodite and its possible relationship to a blue olivine inclusion in a diamond macle (i.e., a spinel-law twinned crystal) which she had obtained for study in early 2011.

\section{Materials and Methods}

\subsection{Synchrotron Radiation and the Diamond Anvil Cell (DAC)}

Shortly after Bill accepted a position in 1979 in the Geology Department at Cornell University, he learned of the university's synchrotron facility, originally designed for the study of electron-positron collisions. Following his arrival, he learned that the synchrotron was undergoing major modifications so that it would become the Cornell High Energy 
Synchrotron Source (CHESS) capable of producing tiny beams of extremely intense X-rays. He reasoned that it should be ideal for collecting X-ray diffraction patterns of the tiny samples at high pressures and temperatures in the diamond anvil cell (DAC) and that the marrying of the DAC to CHESS might be able to produce diffraction data in real time, a process that previously required several days for each diffraction pattern on a conventional X-ray source. It appeared to be an extraordinary but demanding opportunity. The director of CHESS, Boris Batterman, generously allowed a few Cornell faculty to start making runs before the facility was completed and made available for general research proposals. Fortunately, the opportunities also attracted geology students with strong physics background, just what was needed for the challenging tasks ahead for designing instrumentation to make the best use of the remarkable properties of synchrotron-generated X-rays. With the help of his student, Mike Furnish, Bill was able to design a system that would be able to make the best use of the combined CHESS-DAC system so that they would be able to collect real-time diffraction data while they changed pressure and/or temperature from the desk/console outside the experimental hutch. In addition to precise control over pressure and temperature, we wanted to be able to create shear stress in our samples.

\subsection{Shear-Stress Experiments}

Furnish and Bassett had tried to generate shear stress at high pressure by rotating one flat anvil face as it is pressed against the sample and the opposing flat anvil face as that anvil was held immobile but found it to be unnecessary due to olivine's ductility at high pressure and high temperature. In fact, olivine is so ductile at high pressures and temperatures that radial extrusion of the sample toward the edges provided ample, symmetrical shear-stress distribution increasing from zero at the center to a maximum at the edges of the sample. A deformable soft metal gasket surrounding the sample or a slightly reducing environment was used to protect samples susceptible to oxidation. The sample was heated by resistance using either 0.125 -mm-diameter molybdenum (Mo) wire or $0.250-\mathrm{mm}$-diameter Mo wire. The wire was wound around the tungsten carbide (WC) seats supporting the diamond anvils. A coating of ceramic cement on the WC seats electrically insulated the Mo wires from the WC. The excellent thermal conductivities of WC and diamond provided very stable temperatures at the sample with minimum loss of heat. Thermocouples in contact with the upper and lower diamond anvils accurately registered the temperature of the sample. More details of these design features can be found in Reference [3]. The pattern of extrusion could easily be observed by the radial outward migration of irregularities in the sample when observed at high pressure and temperature under a microscope. It was nearly symmetrical when the diamond anvils remained perfectly aligned. That configuration would clearly provide the ideal setting for promoting the displacive, martensitic-type, transition suggested by Poirier [1]. We chose to call it "shear deformation" in order to avoid confusion with the terms "martensite" and "martensitic", terms originated for and more commonly used in the descriptions of metal phase transitions. More details of these design features can be found in Reference [3].

In addition to the stress/strain gradient, a pressure gradient develops from highest in the center to lowest toward the edges as extrusion causes thinning of the sample toward the edges (Figure 1).

\subsection{X-ray Diffraction Experiments with Intense Synchrotron White X-ray Beam}

Furnish and Bassett [2] prepared several samples of fayalite which they mounted within $0.125-\mathrm{mm}$ thick brass or stainless-steel gaskets to protect the samples from oxidation. Similar experiments made in later studies were protected from oxidation by employing a slightly reducing Ar: $1 \% \mathrm{H}_{2}$ mixed-gas environment. Figure 2 shows the arrangement of the most important components in the experimental hutch at CHESS with distorted sizes for emphasis. The team wanted to have a very tight control over the rate at which pressure was increased, as well as a chance to halt at even the slightest indication of a change. 
The desired tight control was achieved with the use of worm gears, as well as standard gears. It was found that a selsyn driver and motor provided the desired control from the workstation, although it did call for a lot of cranking. This was a source of amusement for staff and other users passing by; however, it did provide us with enough control so that we could proceed gradually from step 1 (the restacking of oxygen atom layers) to step 2 (diffusive reordering of cations to spinel crystal sites) with as many increments as we needed. We recorded the X-ray signal at a fixed $2 \theta$ angle by multichannel analyzer so that we could view the entire diffraction pattern simultaneously at each pressure by using energy-dispersive $\mathrm{X}$-ray spectroscopy.

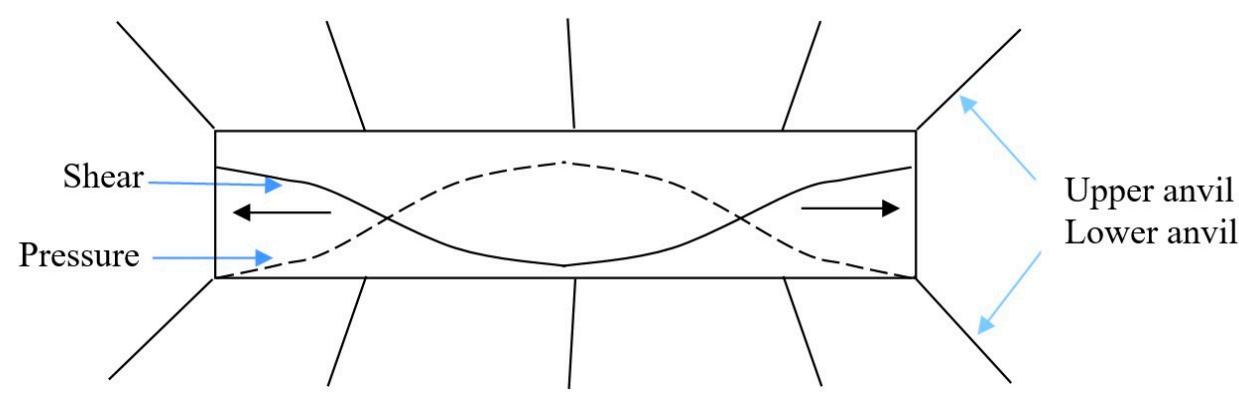

Figure 1. Side view of the diagrammatic plot of shear deformation. Horizontal arrows indicate extrusion of ductile sample. The solid line represents magnitude of shear deformation versus diameter of the sample, and the dashed line represents pressure versus diameter of the sample.

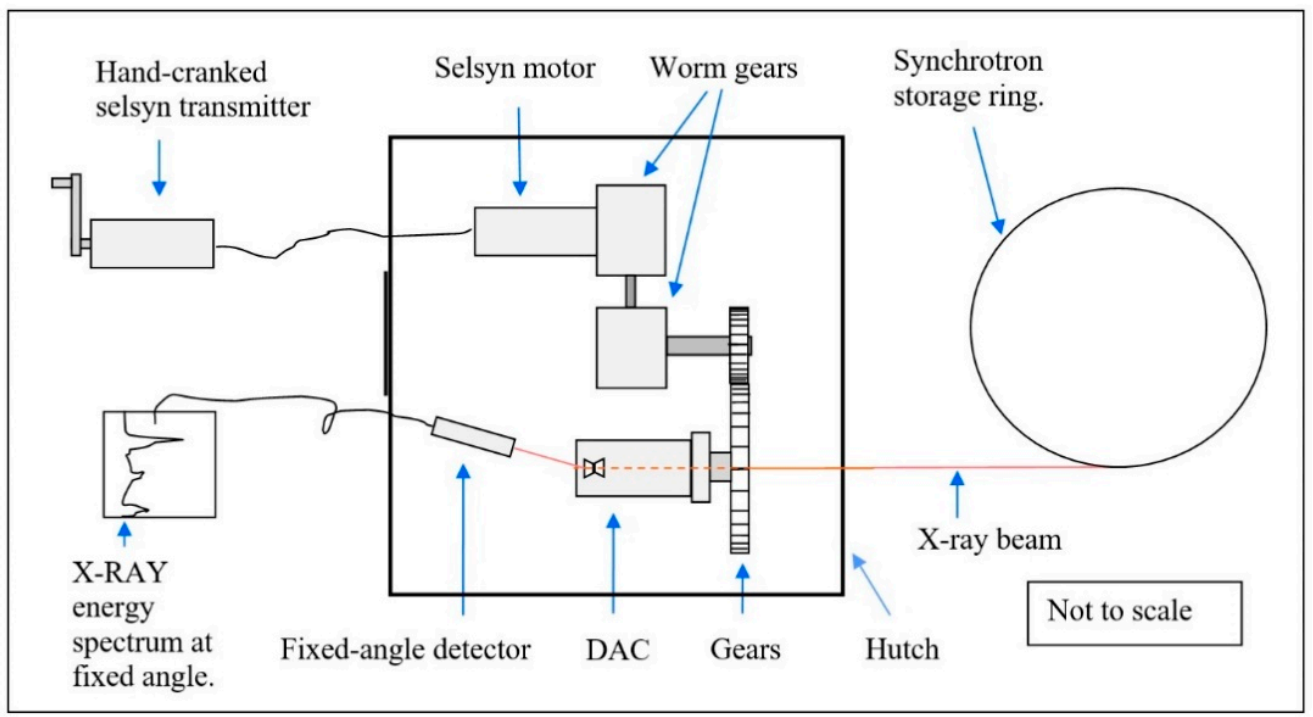

Figure 2. General arrangement of the components for the synchrotron radiation experiment with distorted sizes to emphasize the items most important to the experiments.

\section{Results}

\subsection{X-ray Diffraction}

We chose fayalite, the iron-rich endmember of the olivine series, because its transition pressure is the lowest in the olivine series. It immediately became apparent that the phase transition from the olivine structure, $\alpha \mathrm{Fe}_{2} \mathrm{SiO}_{4}$, to ringwoodite's spinel structure, $\gamma \mathrm{Fe}_{2} \mathrm{SiO}_{4}$, took place in two steps when pressure was gradually increased. In each run, we were pleased to find that we were able to record the diffraction pattern of sample intermediate between step 1, the displacive sliding of the layers of oxygen atoms, and step 2, the diffusion of cations to the newly established sites in the spinel structure, by quenching the sample to $25^{\circ} \mathrm{C}$ approximately midway between the two steps. This allowed 
us to obtain Debye-Scherrer diffraction patterns of all three stages and mount them sideby-side so that direct visual comparisons could be made (Figure 3). The fact that $\mathrm{Fe}_{2} \mathrm{SiO}_{4}$ also transforms by disproportionation to wustite $(\mathrm{FeO})+$ stishovite $\left(\mathrm{SiO}_{2}\right)$ mixture at a still higher pressure [4] did not interfere with observations of the $\alpha-\gamma$ transition. In fact, it helped to define the radial pressure gradient.

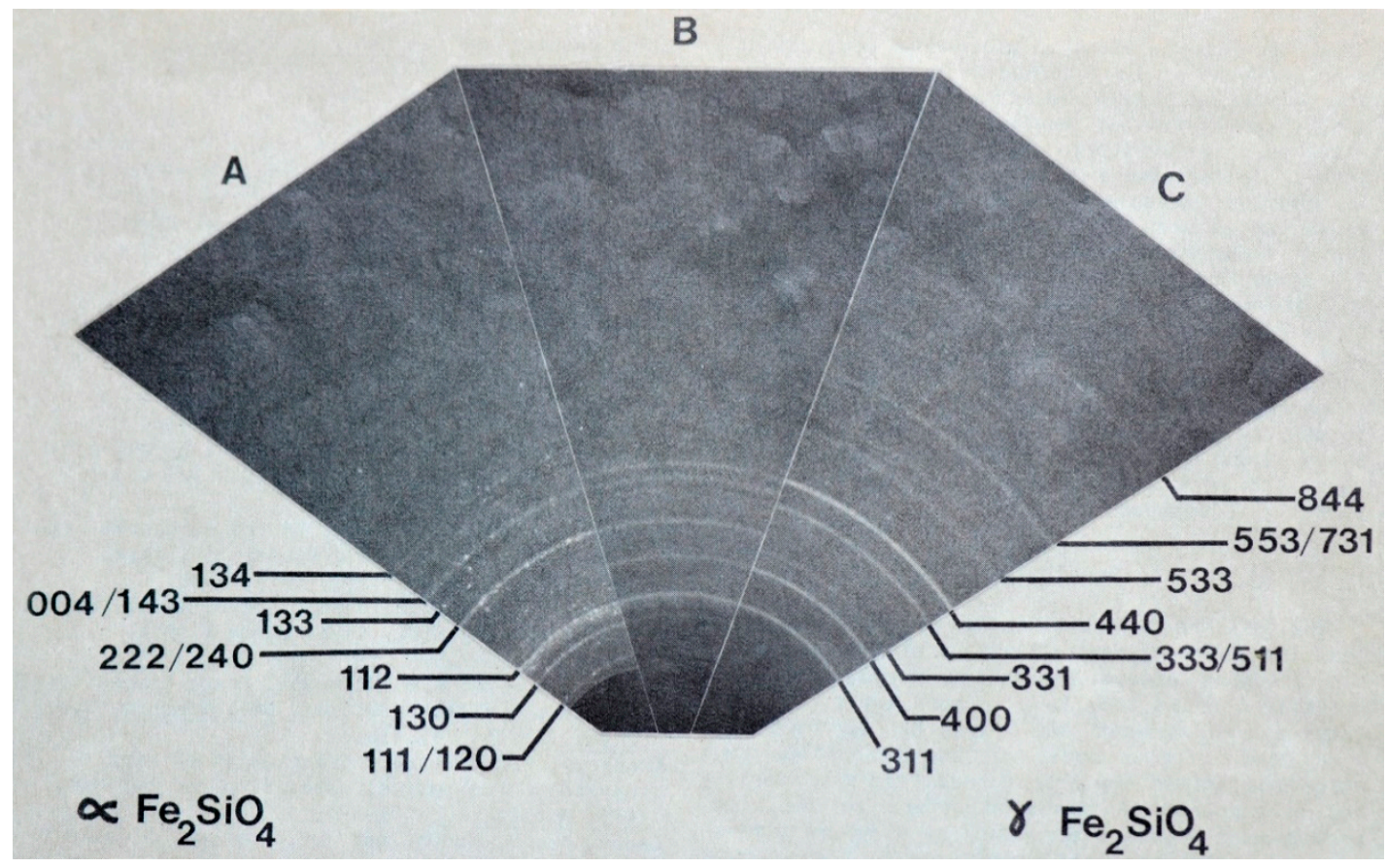

Figure 3. Three Debye-Scherrer diffraction patterns: (A) the left pattern is the olivine ( $\alpha$ phase) from just before step 1, i.e., before shear deformation initiated the transition; (B) the middle is the pattern of sample quenched midway between step 1 and step 2; (C) the right pattern is of sample quenched after step 2, i.e., after thermal diffusion had produced the diffraction pattern of the $\gamma$ phase or the $\gamma$ phase with some residual disordered cations [2] (Figure 8). The ductile shear deformation of the sample resulting from the shear stress played the important role of driving the shear-induced phase transition, step 1, that we observed. The term "shear deformation" is used because the effects of stress and plastic strain cannot be independent of each other when pressure is applied to a very ductile sample. Background irregularities in the upper portions of the diffraction patterns occurred in the original photographic Debye-Scherrer patterns and have no bearing on sample structure.

The sample intermediate between step 1 and step 2 in Figure 3 was especially interesting because it provided an opportunity to carefully follow changes initiated by Step 1 . Important features observed in this comparison are the extensions of the superimposed $\alpha$-phase lines of Miller indices, superimposed (004)/(143), superimposed (222)/(240), and (130) which extend into the intermediate sample between step 1 and step 2 but with less intensity. And they do not extend beyond step 2. Likewise, the $\gamma$-structure miller indices (440), (331), and (400) lines appear between step 1 and step 2 and extend beyond step 2 into the $\gamma$-phase diffraction pattern with increased intensity. We also examined the intermediate diffraction patterns not only by quenching but also by observing multiple patterns obtained by energy spectra during progress from step 1 to step 2.

We then plotted ratios of intensities of emerging $\gamma$-phase miller indices (331):(400), which is insensitive to cation ordering and in contrast (440):(400), which is sensitive to cation ordering between step 1 and step 2 (Figure 4). We chose to plot areas under the peaks because they are more accurate indicators of intensities than peak heights. Using the series of synchrotron diffraction patterns collected between step 1 and step 2 employing our selsyn method for obtaining pressure increase with very small increments, we interpreted 
the data shown in graphs Figure $4 \mathrm{a}, \mathrm{b}$. Neither of these ratios depends on the absolute quantities of either $\alpha$ or $\gamma$ phase.

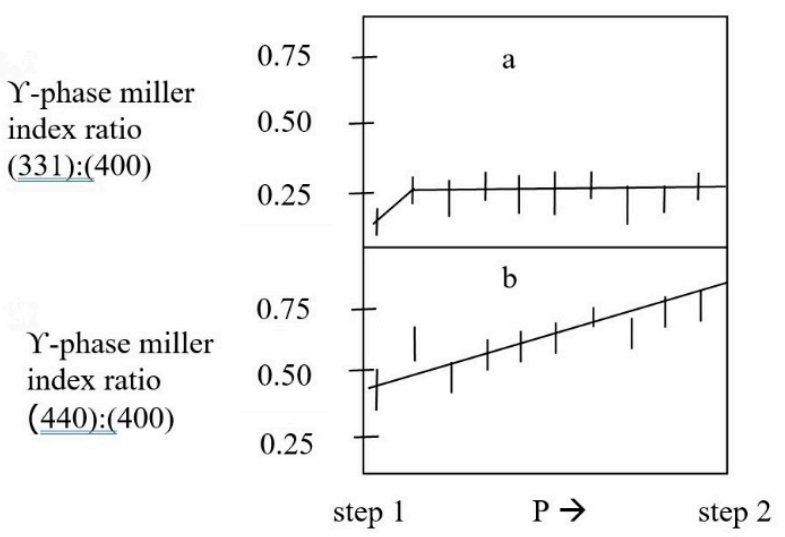

Figure 4. (a) Ratio of $\gamma$-phase miller indices (331):(400) peak areas (insensitive to cation ordering) between step 1 and step 2. (b) Ratio of $\gamma$-phase miller indices (440):(400) peak areas (sensitive to cation ordering) between step 1 and step 2 at $500{ }^{\circ} \mathrm{C}$. Modified from Reference [2] (Figure 7).

Although we observed mixed $\alpha$ and $\gamma$ phases between step 1 and step 2, the sharpness of the lines in the Debye Scherrer patterns and narrowness of the peaks in our synchrotron diffraction patterns indicate little broadening that can result from intimate random mixing of the two phases. The sharpness of diffraction lines in Figure 3 is indicative of the type of mixing of $\alpha$ and $\gamma$ phases shown in Figure 5, where the layers of phases are likely an indication of stacking of phases hundreds to thousands of oxygen layers in each of the phases. This, however, does not preclude residual cation disorder consisting of $\mathrm{Fe}$ and $\mathrm{Si}$ cations occupying both 4 -fold and 8-fold coordination sites resulting from shear deformation as the ratio of $\alpha$ and $\gamma$ phases increases, as indicated by Figure $4 \mathrm{~b}$.

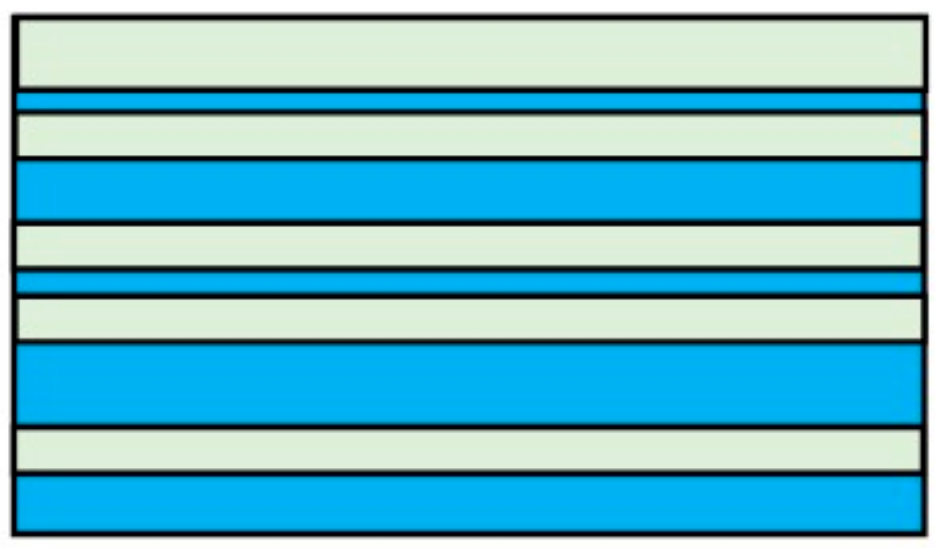

Figure 5. Diagram of random stacking of $\alpha$-olivine phase (green) and $\gamma$-ringwoodite phase (blue). As pressure and shear deformation increase, repeated cycles of step 1 and step 2 proceed, and the ratio of $\gamma$ to $\alpha$ phase abundance increases. In addition, there is initially an increasing number of boundaries that undergo translational displacement or sliding. The nature and consequences of this mechanism are discussed in the next section.

\subsection{Crystal Structures}

3.2.1. The $\alpha$ and $\gamma$ Structures Viewed Normal to the Oxygen Close-Packed Layers

This section presents the transition of crystal structure from step 1 olivine ( $\alpha$ ) (Figure 6) to step 2 spinel $(\gamma)$ (Figure 7) with the intermediate stage between step 1 and step 2 (Figure 8). 


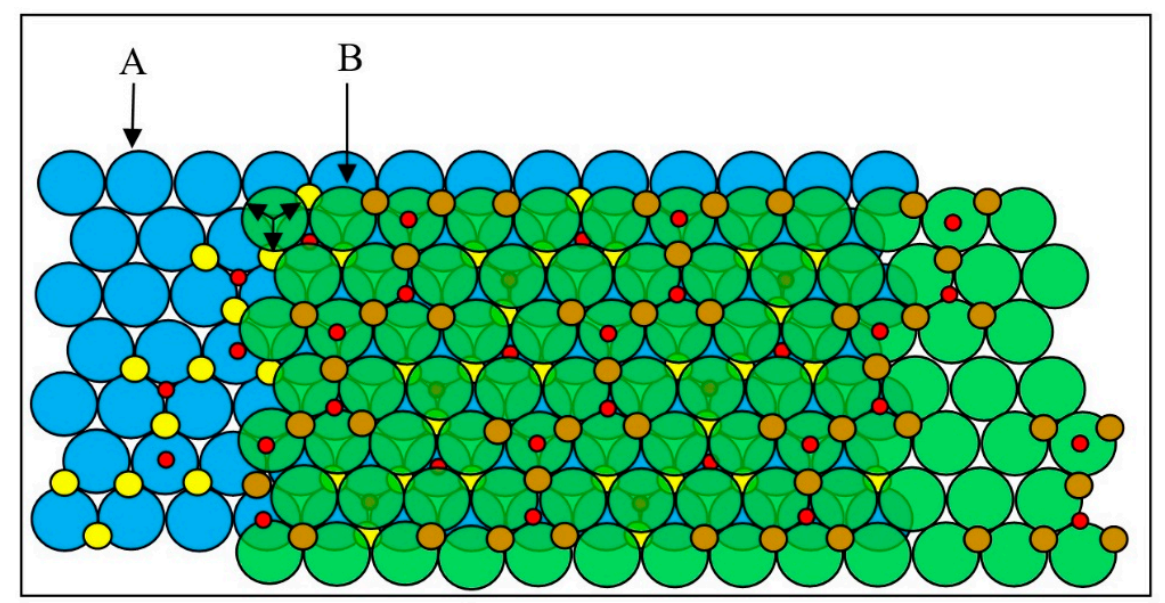

Figure 6. Olivine $(\alpha)$ crystal structure. The pre-step 1 ABAB stacked layers of oxygen atoms slightly distorted hexagonal close packing (hcp) in olivine $(\alpha)$ structure. Blue (A) is the lower layer of oxygen atoms; green (B) is the upper layer of oxygen atoms; yellow is first-layer mixed $\mathrm{Mg}$ and Fe ions; brown is second-layer mixed $\mathrm{Mg}$ and Fe ions; red is silicon atoms. Upper layer is shifted to right one repeat distance to aid vizualizing. The three arrows indicate directions the top layer can slide in step 1, the displacive (martensitic-like) transition.

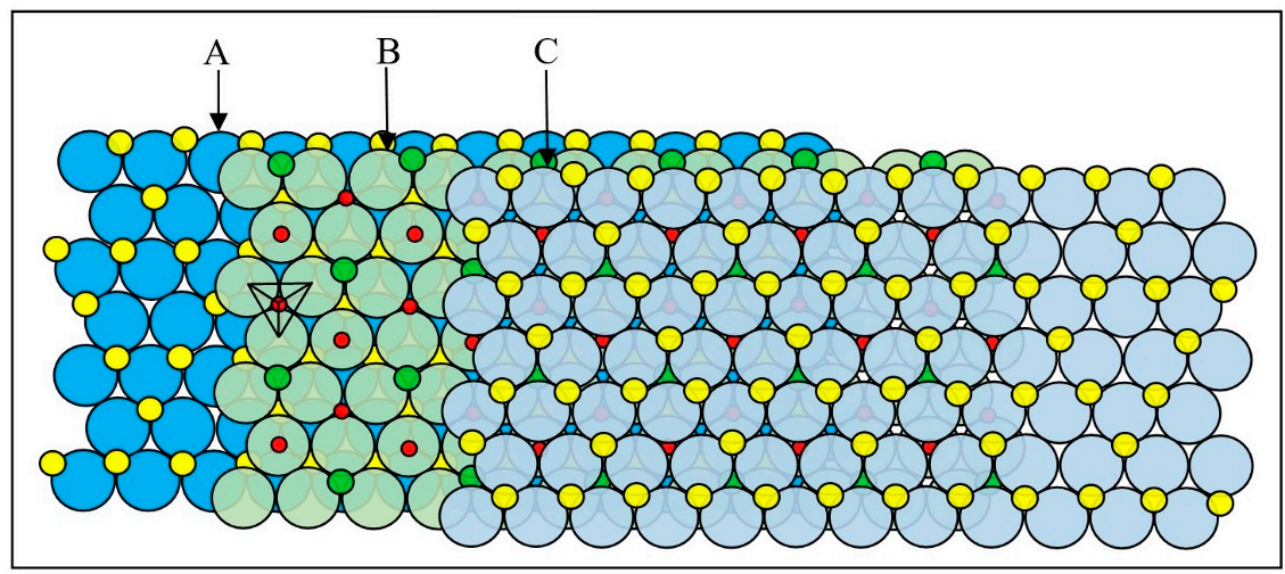

Figure 7. Spinel $(\gamma)$ crystal structure post-step 2 ABCABC stacked layers of oxygen atoms in cubic close packing (ccp) found in the spinel (ringwoodite) $(\gamma)$ structure. Dark blue, green, and light blue are ABC oxygen atoms, respectively; yellow and green are mixed $\mathrm{Mg}$ and $\mathrm{Fe}$ cations; red is $\mathrm{Si}$; tetrahedron is $\mathrm{SiO}_{4}$ polyhedron.

\subsubsection{View Parallel to Gliding Oxygen Layers}

Even a cursory examination of Figures 8-10 reveals that there is no immediate guidance that would avoid disordering of the cations in the first step without a second step capable of ordering them. That second step requires the movement of the cations to the newly created cation sites in the $\gamma$-phase. In other words, the two steps of the transition must be very different mechanisms, and the oxygen-layer restacking must precede the cation reordering if the cations are to "know where to go". The most logical mechanism for the second step is thermal diffusion of the cations to the "proper" octahedral and tetrahedral sites in the new $\gamma$ arrangement of oxygen atoms. 


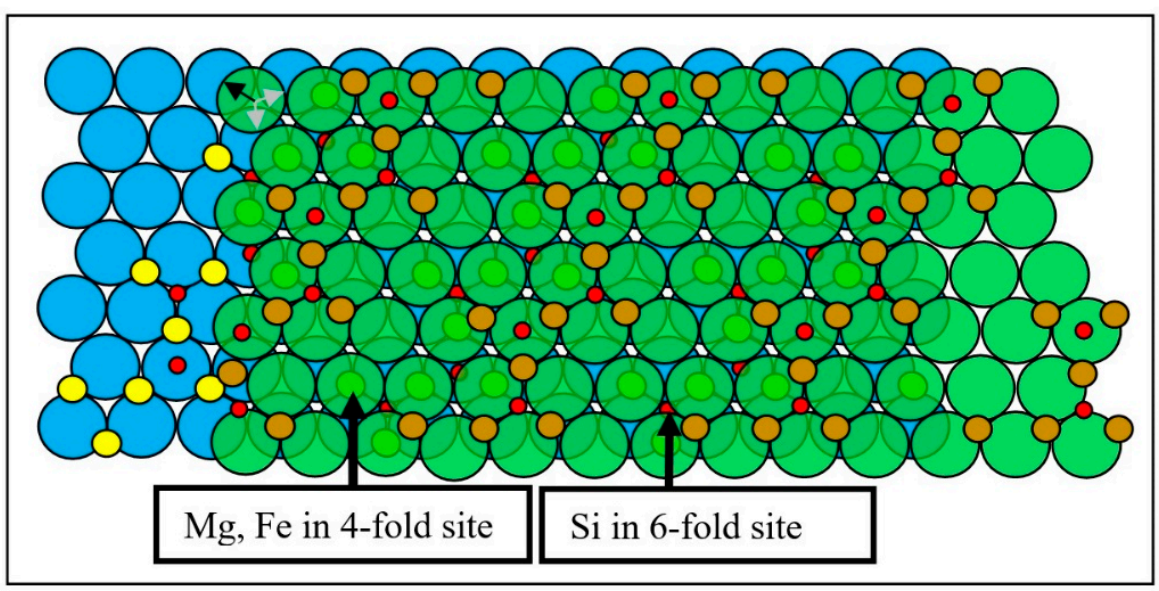

Figure 8. Details of the step 1 displacive sliding mechanism. Blue (A) is lower layer of oxygen atoms; green (B) is upper layer of oxygen atoms; yellow is first-layer of mixed $\mathrm{Mg}$ and Fe ions; brown in second-layer of mixed $\mathrm{Mg}$ and Fe ions; red is silicon atoms. To transform from the ABAB stacking of oxygens in the $\alpha$ phase to $\mathrm{ABCABC}$ stacking in the $\gamma$ phase, some of the layers must slip in one of three directions. In this diagram, the black arrow in the upper left corner indicates the direction the upper layer has been displaced; the gray arrows indicate the directions not taken. No matter which direction, some Si ions end up in misfit 6-fold sites, and some $\mathrm{Mg}$ and Fe ions end up in misfit 4 -fold sites.

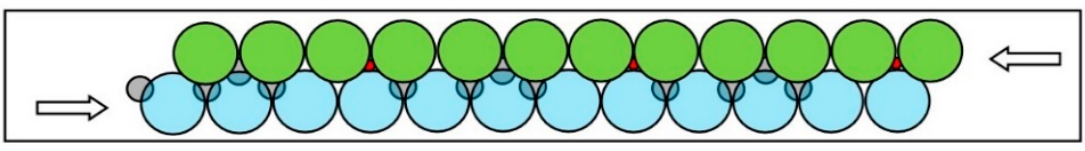

Figure 9. This is an illustration of just two of the layers in the $\alpha$-phase that would need to slide over each other when going from the distorted hexagonal close packed (hcp) arrangement in $\alpha$-phase to the ccp arrangement in $\gamma$-phase. This is what we hypothesize as the change resulting from shear deformation in step 1.

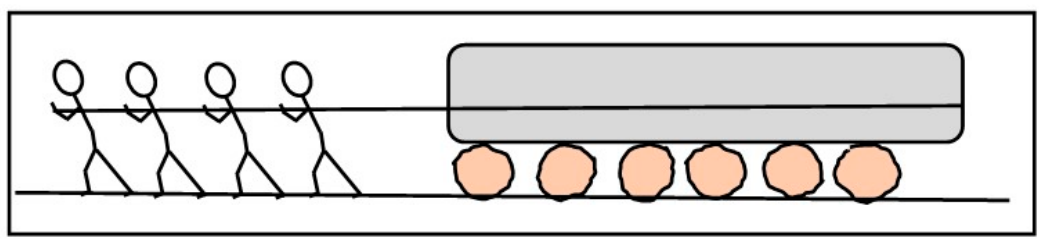

Figure 10. Illustration of step 1 of the shear-induced displacive restacking of the oxygen layers.

It is difficult to see how this two-step process can avoid resulting in cation disorder. Moreover, it is possible that a handful of remaining misplaced cations could make ordering of the cations to the $\gamma$ phase impossible for completing the cation ordering process to ever be achieved, especially in the case of inadequate temperature. Cation disorder is especially likely when we consider that the bonding strengths for tetrahedral 4-fold and octahedral 6 -fold sites must differ, as well as the bond strengths for +4 valence of $\mathrm{Si}$ and the +2 valence of $\mathrm{Mg}$ and $\mathrm{Fe}$.

We cannot help thinking that sliding one layer over another would be like rolling a large rock on a set of irregular logs, such as a block on its way to a pyramid or perhaps an Easter Island moai on its way to a pedestal by the coast.

\subsection{Visual Observations in the DAC}

\subsubsection{Fayalite}

Ten years after the synchrotron experiments, Pamela Burnley, who had worked with Harry Green at University of California at Davis on the olivine-ringwoodite transition 
and its role in deep-focus earthquakes [5,6], joined our research group. Together, we revisited the olivine-ringwoodite transition. Once again, we chose fayalite because of the relatively low pressure of the $\alpha-\gamma$ transition and because it was the sample that Furnish and Bassett [2] had studied by synchrotron X-ray diffraction.

Once again, we loaded a fayalite sample in a soft metal gasket (brass or stainless steel) to allow extrusion of the sample while protecting it from oxidation as Furnish and Bassett had for the 1983 X-ray experiments [2]. As we slowly increased the temperature, extrusion of the sample toward the edges established a pressure gradient from highest in the center to lowest toward the edges due to thinning of the sample toward the edges (Figures 1 and 11).

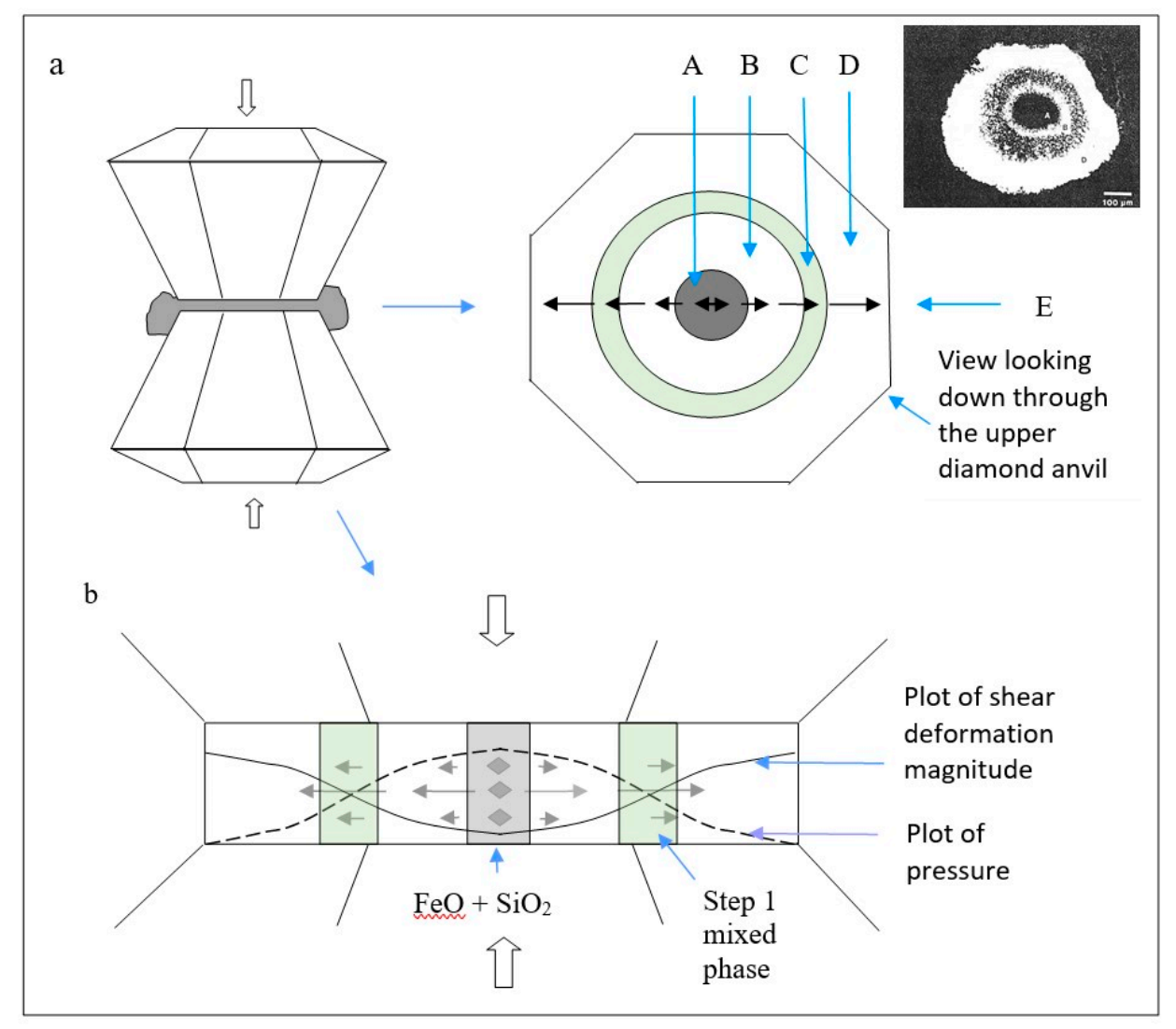

Figure 11. (a) Diagram of fayalite compressed between the flat faces of diamond anvils at $520{ }^{\circ} \mathrm{C}$. (A) High-pressure $\mathrm{FeO}$ plus $\mathrm{SiO}_{2}$ disproportionation [4] unaffected by shear; (B) sample with pressure just below hydrostatic transition, but with shear deformation less than needed for the $\alpha-\gamma$ transition; (C) the appearance of the $\gamma$ phase driven by shear deformation; (D) fayalite sample at too low a pressure for any phase transitions to occur; (E) arrows illustrating the increasing shear deformation toward the edges of the diamond anvils. The temperature was uniformly $520{ }^{\circ} \mathrm{C}$ over the entire sample area. (b) Side view with arrows showing the shear deformation and the plot of pressure and shear deformation magnitudes across the sample diameter as shown in Figure 1. The inset [7] (Figure 2) shows an image of the sample that is shown schematically in (a).

In Figure 11, the $\mathrm{FeO}-\mathrm{SiO}_{2}$ disproportionation reaction [4] is reconstructive and is not expected to be affected by the presence of shear stress. The sample thickness thinned toward the edges (Figures 1 and 11), while temperature remained uniform over the entire sample, due to diamond's excellent thermal conductivity. At the same time, the extrusion established a gradient of shear deformation with the minimum at the center of the sample and increasing toward the edges. For these observations, we chose to increase the temperature rather than the pressure and were rewarded by observations very similar to the previous results. Gradual raising of the temperature then allowed us to visually 
observe simultaneous effects of pressure and shear deformation displayed as a geometric relationship all in the same sample (Figure 11a). We made sure that the resulting central maximum pressure would be close to the transition pressure based on previously observed transition pressure Table 1. Gradual raising of the temperature allowed us to visually observe simultaneous effects of pressure and shear deformation displayed as geometric relationships in the visually observed sample (Figure 11a).

Table 1. Five samples with $\alpha$-phase structure [8].

\begin{tabular}{cccc}
\hline Sample & $\begin{array}{c}\text { From Literature } \\
\text { "Hydrostatic", }\end{array}$ & $\begin{array}{c}\text { In DAC Experiments } \\
\text { "Nonhydrostatic", }\end{array}$ & Difference \\
\hline $\mathrm{Mg}_{2} \mathrm{SiO}_{4}$ & $700^{\mathrm{a}, \mathrm{b}}$ & $575^{\mathrm{c}}$ & $>125$ \\
$\mathrm{Mg}_{2} \mathrm{GeO}_{4}$ & $860^{\mathrm{d}}$ & $600^{\mathrm{e}}$ & $>260$ \\
$\mathrm{Ni}_{2} \mathrm{SiO}_{4}$ & $650^{\mathrm{f}}$ & $525^{\mathrm{e}}$ & $>125$ \\
$\mathrm{Co}_{2} \mathrm{SiO}_{4}$ & $800^{\mathrm{g}, \mathrm{h}}$ & $525^{\mathrm{e}}$ & $>275$ \\
$\mathrm{Fe}_{2} \mathrm{SiO}_{4}$ & $600^{\mathrm{i}, \mathrm{j}}$ & $380^{\mathrm{c}}$ & $>220$ \\
\hline
\end{tabular}

a Suito, 1977 [9]; ${ }^{\mathrm{b}}$ E Ito, 1991 [10]; ${ }^{\mathrm{c}}$ Wu et al., 1993 [7]; ${ }^{\mathrm{d}}$ Burnley, 1990 [11]; ${ }^{\mathrm{e}}$ Burnley et al., 1995 [8]; ${ }^{\mathrm{f}}$ Rubie personal communication, 1994 [12]; ${ }^{\mathrm{g}}$ Ringwood, 1963 [13]; ${ }^{\text {h }}$ Akimoto, 1970 [14]; ' Ringwood, 1958 [15]; ${ }^{j}$ Yagi, personal communication, 1991 [16]; * Some of these values may be low due to inadvertent shear stress in some high-pressure devices.

\subsubsection{Other Samples with Olivine Structure}

Burnley, Bassett, and $\mathrm{Wu}$ [8] then ran the same experiment on other $\alpha$-phase specimens (Table 1), making sure the pressure at the center of the sample was close to the published values needed for the $\alpha-\gamma$ hydrostatic transitions for each composition. As temperature was increased, they observed the $\gamma$-phase by color change and by Debye Scherrer diffraction patterns. The same relationships appeared in all of the silicate olivine compositions, as well as the $\mathrm{Mg}_{2} \mathrm{GeO}_{4}$. That is, in all cases, the high-pressure $\gamma$ phase appeared as an annulus with the low-pressure phase both inside and outside of the annulus [7,8]. This geometry is consistent with our earlier results as we realized that the low-pressure region outside of the ring was too low, and the shear deformation inside the ring was too low, to promote the $\alpha-\gamma$ transition. It gave us a clear picture of the need for pressure, temperature, and shear deformation to be high enough to promote step 1 of the $\alpha-\gamma$ transition, displacive ordering of the oxygen layers. In other words, the first step of the transition occurred only where the pressure plot and the shear stress/strain plot cross.

All of these research projects on this topic since the 1983 Furnish and Bassett [2] paper revealed the importance of shear deformation in promoting the transition. Figure 11 represents the observation diagrammatically in order to avoid any distraction due to sample irregularities. A small image of the fayalite sample with a soft metal gasket as it was observed is shown as an inset in Figure 11.

The sample near the edges had too low a pressure, while the sample in the center with the highest pressure was subjected to too little shear stress and resulting ductile strain, thus illustrating the exceptionally large influence of shear deformation to promote step $\mathbf{1}$ of the phase transition even at the higher-pressure portion in the center of the sample. We also ran this experiment for several silicate and germanate compositions Table 1. Conventional in situ X-ray diffraction rather than synchrotron radiation was used to identify the phases and pressures. Visual observation was the principal technique used. In Figure 11, area $\mathrm{B}$ is the most interesting because it clearly shows that there is a large range of pressure separation between the $\alpha-\gamma$ transition caused by shear and the reconstructive disproportion reaction $[2,6]$.

Given this, the present authors postulate that it is entirely plausible that much of the ringwoodite in the mantle never rose to a high enough temperature for the $\alpha-\gamma$ transition to have proceeded to completion resulting from the second step of diffusion of the cations. In other words, the spinel phase may never have proceeded to completion, and many cations may have remained disordered, giving ringwoodite some of its unusual properties. 


\section{Wadsleyite, Ahrensite, and Asimowite}

Wadsleyite is a stable high pressure-temperature phase with a composition range from $\mathrm{Mg}_{2} \mathrm{SiO}_{4}$ to $\mathrm{Mg}_{1.2} \mathrm{Fe}_{0.8} \mathrm{SiO}_{4}$ in the pressure range from $13 \mathrm{GPa}$ to $21 \mathrm{GPa}$ at $1600{ }^{\circ} \mathrm{C}$. Wadsleyite has the spineloid structure $(\beta)$ which is very similar to the spinel-structure of ringwoodite $(\gamma)$. The spineloid structure differs from the spinel structure only by a different ordering of the cations in the same ccp arrangement of the oxygen atoms [17]. For that reason, we treat both wadsleyite and ringwoodite phases as having the same 2-step phase transition from olivine.

The high-pressure spinel-structure phase of fayalite was named ahrensite in honor of Thomas Ahrens, California Institute of Technology [18]. Because the iron-rich composition of ahrensite appears to have no significant bearing on the nature of the transition mechanism of the $\alpha-\gamma$ or the $\gamma-\alpha$ phase transition, we have not made a distinction between the forsteritic and fayalitic compositions.

Bindi et al. [19] report the first natural occurrence of the Fe-analog of wadsleyite, which they named asimowite in honor of Paul D. Asimow, Professor of Geology and Geochemistry at the California Institute of Technology. As it too is a spineloid, it is expected to have a similar 2-step phase transition as wadsleyite.

\section{Sequence of Step 1 and Step 2 Transition}

In his book, Introduction to the Physics of the Earth's Interior, Second Edition [20], Poirier (pp. 251-255) provides a summary of experimental studies of the $\alpha$-olivine transition to $\beta$-wadsleyite and /or $\gamma$-ringwoodite. In his discussion, he points out that some studies, especially ones conducted in multianvil pressure devices, did not observe disordered cation distributions, while studies conducted in some high-pressure devices, such as diamond anvil cells, were more likely to result in disordered cation distributions. He attributes these differences to the amount of shear stress which, as he points out in Reference [20], may depend on the degree of shear stress when shear stress is present. Thus, the evidence that step 1 must precede step 2 in the presence of shear stress with a temperature difference as high as $200^{\circ} \mathrm{C}$ is convincing. The displacement of oxygens from the distorted hexagonal close-packed (hcp) layers of $\alpha$-olivine to the cubic close-packed (ccp) layers of $\beta$-wadsleyite and $\gamma$-ringwoodite must precede step 2, the thermal diffusion of cations to the "proper" sites of either new $\beta$ or new $\gamma$ phase.

On the other hand, evidence that step 1 precedes step $\mathbf{2}$ in the absence or very low level of shear stress, as suggested below, is more speculative. The basis for suggesting the same sequence of step $\mathbf{1}$ followed by step $\mathbf{2}$ even in the absence of shear deformation concerns the nature of the two steps of the transition mechanism, as it is hard to see how the diffusion of cations (step 2) can precede displacement of oxygen layers (step 1) when it is the displacement mechanism that eliminates the previously occupied cation sites and establishes new sites at the "proper" locations in the new phase. We acknowledge that the time separating the two steps may be so short as to resemble a simple one-step reconstructive transition.

\section{Implications of the Shear Induced Phase Transition}

The results of these studies and interpretations may have a bearing on the exceptional ability of wadsleyite and ringwoodite to accommodate the large quantities of water found to exist in Earth's mantle. Disorder of cations occurring in the cooler interiors of subducting slabs may result in an unbalance of misplaced charges leading to the commandeering of primordial or subducted hydrogen. Deep-focus earthquakes may be affected not only by the ductility of olivine, wadsleyite, and ringwoodite but also influenced by cation disordering and hydration. In addition, this source of disordered cations in $\beta$ and $\gamma$ phases (Figure 4a) may aid our understanding of the evolution of the properties of wadsleyite and ringwoodite, including the interesting discovery that wadsleyite and ringwoodite are capable of hosting large amounts of water [21-25]. 
In addition, Burnley and Green [5], Burnley et al. [6], and other seminal papers make the point that the mechanism of brittle fracturing responsible for shallow earthquakes cannot be the same as the mechanism responsible for deep-focus earthquakes where pressure and temperature are so high that the ductility of the rocks precludes the brittle failure mechanism. Not only the weakness due to ductility but also sudden shear-induced weakening due to the $\alpha-\beta$ or $\alpha-\gamma$ phase transition may play an important role in weakening olivine-rich rock.

\subsection{Blue Olivine Inclusion in Diamond}

In early 2011, Elise became interested in an enigmatic blue crystal inclusion approximately $400-\mu \mathrm{m}$ long by approximately $100-\mu \mathrm{m}$ thick in a spinel-law twinned diamond, a type of crystal also referred to as a macle (Figure 12). This came about through her friendship with mineralogist and chemist John I. Koivula of the Gemological Institute of America (GIA). A world-renowned specialist in the study and identification of inclusions in minerals and gems, John had suspected that the blue inclusion might be ringwoodite, largely on the basis of the strong blue color in synthesized ringwoodite and natural ringwoodite identified in meteorites.

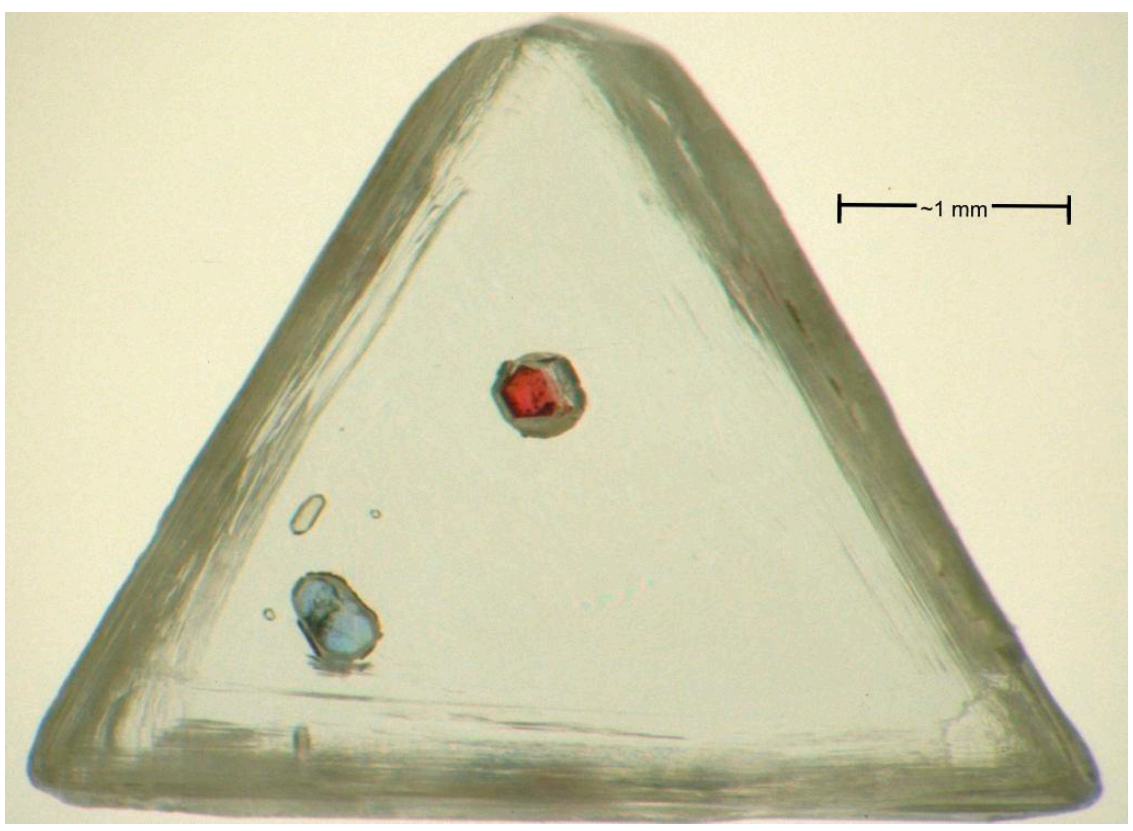

Figure 12. This natural diamond macle from Brazil [26] contains a blue inclusion (400- $\mu \mathrm{m}$ long) and calculated to be approximately 100- $\mu \mathrm{m}$ thick [27] visible in the lower-left corner of the image. The longest dimension along the bottom edge of the diamond is $4.6 \mathrm{~mm}$. In situ X-ray diffraction and fluorescence were used to identify the inclusion as having the olivine structure with forsterite-91 composition [27]. The red inclusion is a nearly euhedral pyrope crystal. Photomicrograph by John I. Koivula; The MicroWorld of Diamonds, 2000 [26] (p. 53).

Because of the diamond host's irregular surfaces which prevented analysis with laboratory instrumentation available to John, along with his unwillingness to destroy the specimen in order to access the blue crystal, as well as knowing of Elise's ongoing collaboration with her co-author, Bill, John approached his friend to offer her the opportunity to see if she and Bill could solve the mystery of the inclusion's identity. John had included a beautiful image of the specimen in his 2000 book, The MicroWorld of Diamonds (Figure 12) [26].

During the next few years after Elise accepted John Koivula's challenge, this blue inclusion in a diamond host led to intensive research, including multiple visits to Cornell University High Energy Synchrotron Source (CHESS), the National Synchrotron Light 
Source (NSLS) at the Brookhaven National Laboratory, the Advanced Photon Source (APS) at Argonne National Laboratory, and the Mineral Physics Laboratory at Northwestern University (NWU) [27]. At each of these facilities, we were assisted by beamline scientists and other staff (see acknowledgments), but it was NWU from which we added the fourth member for our team, Bill's colleague and friend, Steven D. Jacobsen, to make a foursome of John I. Koivula, Elise, Bill, and Steven D. Jacobsen. Steve is responsible along with his colleagues for the beautiful images of synthesized blue ringwoodite specimens that have appeared in numerous journals and more recently in popular literature after ringwoodite was found to have the ability to host large quantities of water.

Our results yielded a number of interesting data, some of which were pertinent to the quest, while others were not. Nevertheless, the observations were very interesting in characterizing the diamond and its inclusions (Table 2).

Table 2. Analytical techniques applied to the study of the inclusions.

\section{Analytical Techniques and Rationale}

- $\quad$ X-ray fluorescence spectroscopy (XRF) (synchrotron) was used to determine composition of the blue inclusion. The diamond host did not interfere with this analysis.

- Multi-orientational monochromatic X-ray diffraction (XRD) (conventional) for identification and overview

- $\quad$ Single crystal XRD (conventional) for detailed structural data showing that the blue inclusion has the crystal structure of normal forsterite-91.

- $\quad$ X-ray microanalysis (synchrotron) for investigating portions of the specimen.

- $\quad$ X-ray absorption near edge structure (Xanes) spectrometry using emission intensities thus providing the cleanest and greatest absorption intensities (synchrotron)

- Mössbauer spectrometry (conventional) for determining that the blue inclusion contains negligible $\mathrm{H}_{2} \mathrm{O}$.

- X-ray Topography (synchrotron) revealed that the diamond host has distorted lattice orientations, and that each inclusion revealed a halo of different lattice parameters, presumably due to decreasing inclusion pressure.

- $\quad$ X-ray absorption fine structure (XAFS) for studying atomic and electronic structures of a target element. These results revealed too small a concentration of $\mathrm{Cr}$ and oxidation states undesirable for $\mathrm{Cr}$ to serve as a chromophore.

- $\quad$ Fourier transform infrared (FTIR) (synchrotron) was used to establish that the water content of the blue inclusion was negligible.

With the help of beamline scientist Zhenxian Liu, we used the infrared synchrotron beamline at the National Synchrotron Light Source (NSLS) at the Brookhaven National Laboratory (BNL) (Upton, NY, USA) to collect data on the water content of the blue inclusion. The results showed that the inclusion contained no detectable water [27].

We also used the Argonne Mössbauer Lab (Lemont, IL, USA) Facility with help from beamline scientist Ercan Alp to determine the oxidation state of the iron in the blue inclusion. The Mössbauer spectrum indicated that all of the iron in the blue inclusion is in the $\mathrm{Fe}^{2+}$ oxidation state.

X-ray diffraction patterns of the blue inclusion indicated that it has the olivine crystal structure (Multi-orientational monochromatic and single crystal XRD, Bayerisches Geoin- 
stitut, University of Bayreuth, Bayreuth, Germany), while XRF indicated forsterite-91 (Northwestern University, Evanston, IL, USA), with the composition shown in Table 3. Together, these data indicated that the blue crystal exists at zero pressure inside the diamond. We observed interference colors in light scattered from spaces between the inclusions and the host diamond, providing further evidence that the inclusions were at zero pressure. Yet still, the blue color remained a conundrum because, at this size, olivine is normally very light green or colorless, so why would the crystal have the color of ringwoodite and the structure of olivine?

Table 3. XRD Analysis of blue inclusion [27].

\begin{tabular}{cc}
\hline Element & Moles per Four Oxygen Atoms \\
\hline $\mathrm{Ca}$ & 0.00 \\
$\mathrm{Mn}$ & 0.00 \\
$\mathrm{Fe}$ & 0.17 \\
$\mathrm{Co}$ & 0.00 \\
$\mathrm{Ni}$ & 0.01 \\
$\mathrm{Si}$ & 1.00 \\
$\mathrm{Mg}$ & 1.82 \\
\hline
\end{tabular}

Although XRF spectrometry indicated the presence of chromium, a known chromophore in many minerals, the concentration of chromium was too low to account for the intensity of the crystal's blue color. Likewise, cobalt, another well-known chromophore was found to have a negligible concentration (Table 3). Iron was the only chromophore to have a concentration sufficient to result in blue color, but it produced blue color in ringwoodite, not olivine, unless, of course, some iron cations failed to diffuse to the olivine coordination sites, where they would produce pale green rather than blue. The smaller crystals visible in Figure 12 have also been identified by XRD as olivine. However, because of their smaller size, $\sim 1 / 4$ the thickness of the blue olivine crystal, they may fail to appear to have the same blue color. However, their smaller size may also have played another role, as discussed below in Figure 13 and Section 6.1.1.

\subsubsection{Proposed Pressure-Temperature History of the Blue Inclusion}

Figure 13 illustrates the proposed history of the inclusion that might explain its present existence as a blue olivine crystal. Segment A: In this proposed history, we start with a crystal of ringwoodite from the time of encapsulation in a diamond, thus isolating it from volume change as it ascends to the earth's surface. It was expected that a ringwoodite crystal, like most normal solids, will undergo a volume reduction as it is cooled. If, however, the crystal resides at high pressure filling a constant volume cavity, this change is manifested as a drop in pressure rather than a drop in volume. Hence, segment $\mathbf{A}$ is inclined. Segment B: When the ringwoodite crystal experiences the start of the phase transition to olivine structure, the crystal will begin to increase in volume as it begins to transform to the olivine structure, which has a larger molar volume than ringwoodite. However, because of the nearly constant volume of the diamond-host cavity, the volume increase is impeded, and pressure increase compensates for the pressure loss due to cooling. Consequently, according to the Clapeyron equation (Equation (1)):

$$
\mathrm{dP} / \mathrm{dT}=\Delta \mathrm{S} / \Delta \mathrm{V},
$$

where $\mathrm{P}$ is pressure, $\mathrm{T}$ is temperature, $\mathrm{S}$ is entropy, and $\mathrm{V}$ is molar volume. 


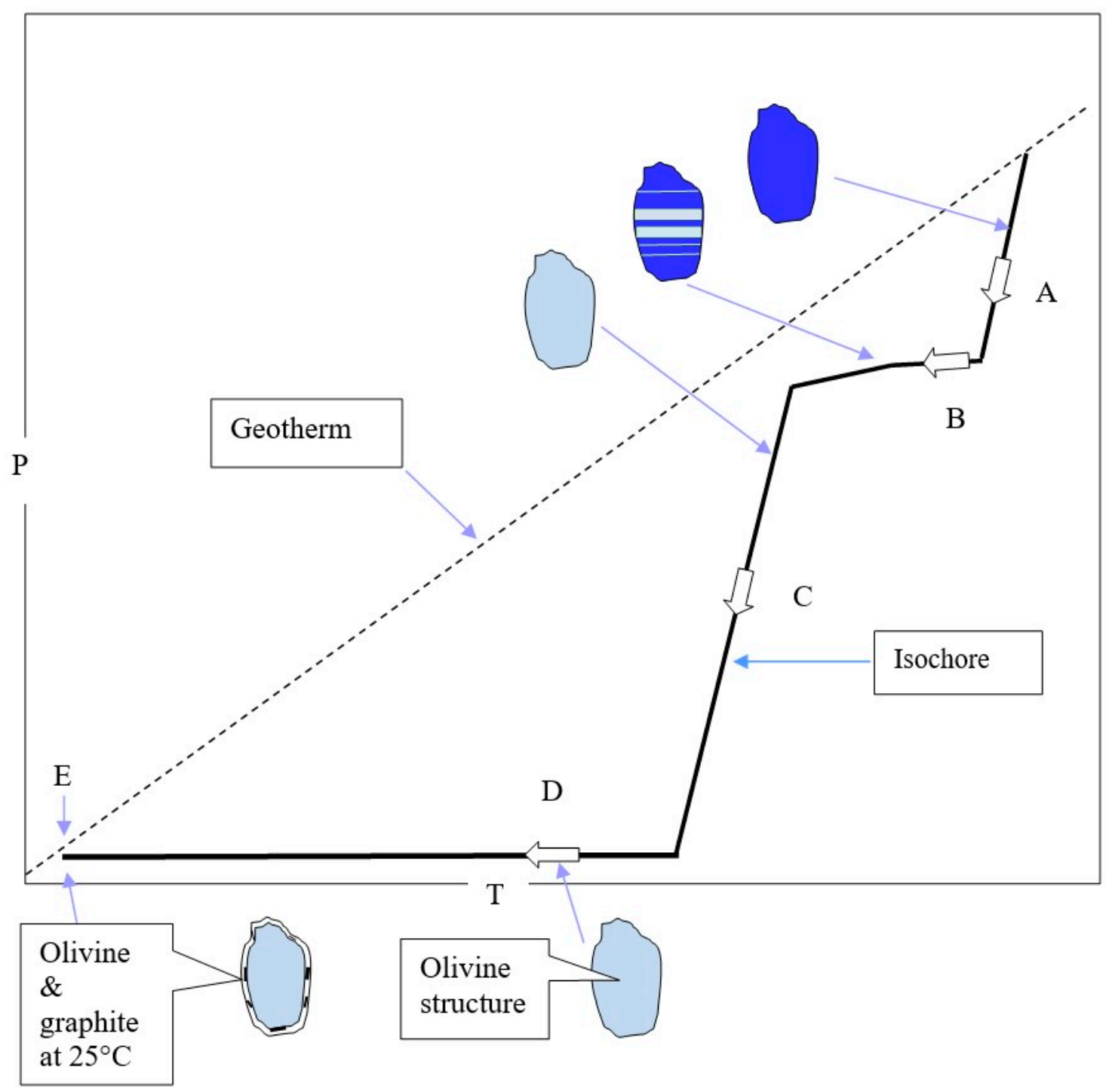

Figure 13. This diagram traces the proposed pressure-temperature history of the blue inclusion. While the volume of a cavity in diamond must undergo some change with pressure and temperature, it is expected to be very minor as a result of diamond's properties. Thus, the assumption that the diamond cavity, and hence the inclusion in it, can be considered to be isochoric, i.e., volume independent of pressure and temperature. This assumption should prove to be satisfactory for the purpose of illustrating qualitatively the suggested pressure, temperature, and crystal structure history from the time a crystal of ringwoodite was trapped in the diamond to its present conditions.

The trajectory becomes nearly horizontal, as shown in segment B. In turn, the drop in temperature impedes the thermal diffusion of cations (step 2), resulting in greater residual cation disorder, as the temperature drops throughout segment B. Segment C: When step 1 of the phase transition is completed, the new crystal with the olivine structure returns to having an inclined plot similar to segment $\mathbf{A}$ as it continues on an inclined trajectory of decreasing pressure versus temperature plot. Segment D: Eventually, the crystal undergoes volume reduction when the phase transition reaches completion until its volume is smaller than the diamond's cavity, and its temperature drops to $25{ }^{\circ} \mathrm{C}$. End Point E: Both X-ray diffraction and interference colors due to space between the olivine crystal and the host-diamond cavity indicate zero pressure of the final crystal at room temperature. A small amount of graphite between the crystal and the host cavity indicates that the high temperature and low pressure during segments $\mathbf{C}$ and $\mathbf{D}$ caused small fragments of diamond to be graphitized. 
If the smaller olivine crystals did proceed along Segment B from $\gamma$ phase to $\alpha$ phase more rapidly than the larger blue crystal, the transition may proceed to completion while the temperature is still high enough for the final phase to reorder all or nearly all of the cations into the $\alpha$ sites, thus eliminating all or nearly all of the blue color.

The occurrence of step 1 prior to step $\mathbf{2}$ in a diamond host may seem counterintuitive because shear stress is unexpected inside of a rigid diamond. However, as explained above, the initial stage of the $\gamma$ phase to $\alpha$ phase transition in segment $\mathbf{B}$ of Figure 13 must be the displacive shifting of oxygen layers, step 1, before the cations can diffuse to the sites in the new phase, the olivine structure in this case. However, the anisotropy of the forming orthorhombic olivine may exert some shear stress, promoting step $\mathbf{1}$ ahead of step $\mathbf{2}$ as the transition progresses. Once triggered, the rate of progress is dependent on the rate of decreasing temperature because of the nearly constant volume of the cavity in the diamond as shown in Figure 13 segment $\mathbf{B}$, thus impeding cation ordering by diffusion. By the time step 1 has proceeded to completion, the temperature may have dropped significantly, possibly too low for step 2, the diffusion of cations, to proceed to completion; thus, resulting in a significant amount of disorder. To be sure, this explanation is speculative as it depends on rates that have not yet been experimentally determined. However, research to date has failed to produce an alternative explanation for the blue olivine inclusion.

Specimens of ringwoodite have been observed to have a wide range of blue intensity due to both iron concentration and specimen thickness. Synthesized specimens of ringwoodite (Figure 14), with less thickness than the inclusion (Figure 12), have been found to have intensities in excess of that for the blue inclusion in (Figure 12). This has important implications for interpretation of the blue inclusion. Iron serves as a much stronger source of blue color in ringwoodite than it serves as a source of green color in olivine, so much so that a specimen only $100-\mu \mathrm{m}$ thick can have a distinctive blue color, whereas a typical olivine crystal only $100-\mu \mathrm{m}$ thick is expected to have no color or only a very faint green color. The concentration of iron in the blue inclusion has been measured as 0.17 moles per four oxygen atoms [27] and shown in Table 3.

\subsubsection{Depth of Formation}

Several analytical tests have been applied to the specimen to establish the depth of its origin. John Koivula identified the red inclusion as chromian pyrope using Raman spectroscopy (page 53) in Reference [26]. Steven Jacobsen, once he had joined the effort to study the specimen, applied additional tests. He confirmed the identification of the red inclusion as chromian pyrope using XRD and XRF. Using FTIR spectra of the diamond itself, Jacobsen determined that the diamond is of type IaAB. That is to say, there are both A and B-type aggregated nitrogen defects, and there is hydrogen. The total nitrogen content is 91 ppm. The presence of A nitrogen aggregates in the diamond indicates that it likely formed in the upper mantle. Likewise, the chromian pyrope instead of majorite, the high-pressure garnet, also indicates an upper-mantle rather than a superdeep origin. Additional evidence for upper-mantle origin is the presence of olivine and lack of ferropericlase, as would be expected at pressures high enough for bridgmanite and ferropericlase to have occurred.

\subsubsection{Synthesized Ringwoodite}

Some very fine specimens have been synthesized at high pressures and temperatures comparable to the conditions in Earth's mantle. Synthetic samples have served as a very important source of information about properties of Earth's interior from color to densities, levels of hydration, sonic velocities, and more. Figure 14 is a photograph of ringwoodite platelets (forterite-82) prepared for making measurements of the amount of bonded water and its effect on sonic velocities [22,27]. The thicknesses and orientations of the samples shown in Figure 14 are especially valuable for our purposes, as well. The intense blue color in these synthesized specimens is attributed to their Fe content. However, unlike the Fe content in the mineral olivine, the Fe source of color is far more intense in the ringwoodite structure than in the olivine structure. Therefore, it should not be surprising that the 
$100-\mu \mathrm{m}$ thick crystal inclusion in the diamond could have the olivine structure and also retain the blue color even if only a portion of misfit Fe ions is retained in the disordered cations inherited from disordered ions of a preexisting ringwoodite crystal.

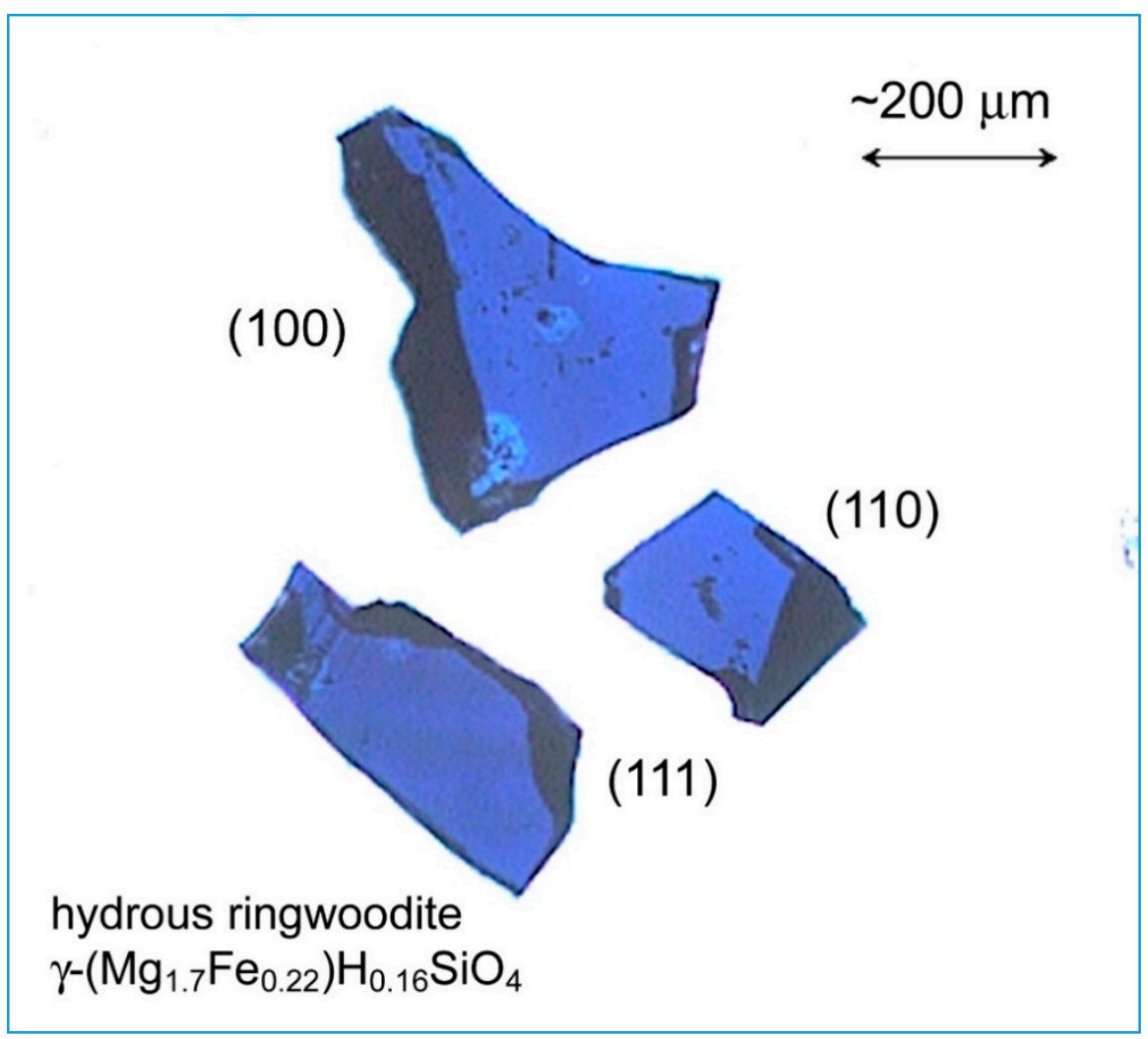

Figure 14. Three platelets of ringwoodite synthesized by Joseph Smyth, University of Colorado, Boulder, CO, USA, prepared for ultrasonic velocity determinations [27]. The three-digit number in each image is the Miller index for the orientations of each one [27]. The platelets labeled (100), (111), and (110) allow viewing along the normal to the polished surfaces of the platelets. 100 and 111 have thicknesses $47 \mu \mathrm{m}$ and $52 \mu \mathrm{m}$. Platelet 110 has an unknown but similar thickness.

\subsubsection{Ringwoodite in Meteorites}

Blue ringwoodite has been found in meteorites and offers additional evidence that the blue inclusion may owe its blue color to residual misfit Fe ions. Figure 15 is a photograph taken by Steven D. Jacobsen of a blue area in Catherwood Meteorite that has been identified as ringwoodite [27-29].

\subsubsection{Blue Olivine in a Pallasitic Meteorite?}

Always on the lookout for interesting specimens, Elise was alerted to another blue olivine enigma by her friend, Dr. Dmitriy Belakovskiy, geologist and curator at the Fersman Mineralogical Museum (Russian Academy of Sciences, Moscow, Russia). She was able to acquire slices from the Seymchan Pallasitic meteorite from the Russian Magadan Oblast, in which the olivine crystal "windows" have small patches that are blue (Figure 16). Knowing that the first naturally occurring high-pressure spinel-phase of $\mathrm{Mg}_{2} \mathrm{SiO}_{4}$ was described in 1968 by Binns et al. [30] and given the mineral name, ringwoodite, in 1979 by Putnis and Price for blue areas of Tenham, a chondritic meteorite [31], Elise recognized that the patches of blue found in the Seymchan Pallasitic meteorite windows might well be ringwoodite or might be yet another example of blue olivine. 


\section{Catherwood ME3066}

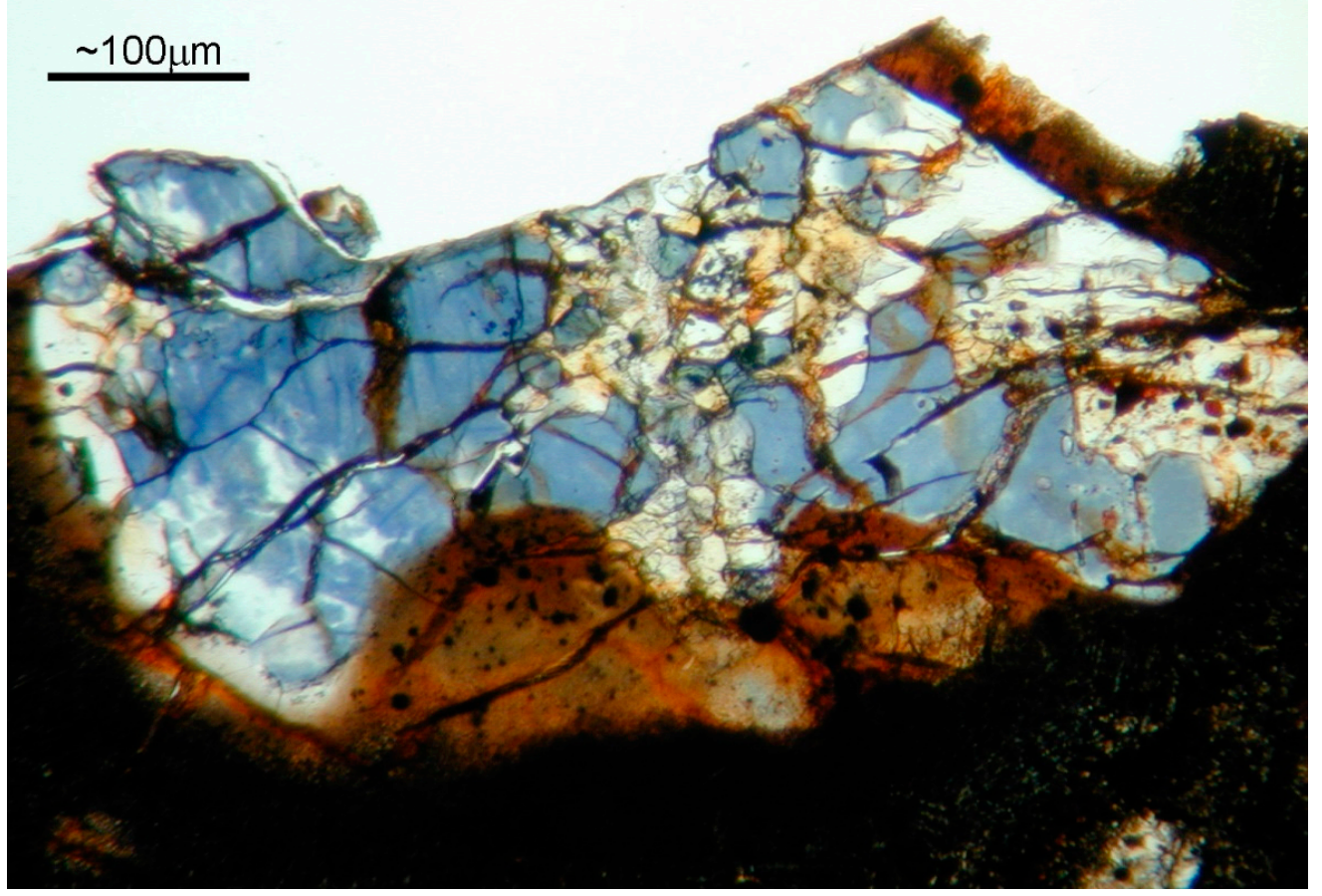

Figure 15. Blue ringwoodite areas in Catherwood Meteorite that have been identified as ringwoodite with composition fayalite-25 [28]. Image by Steven D. Jacobsen [27].

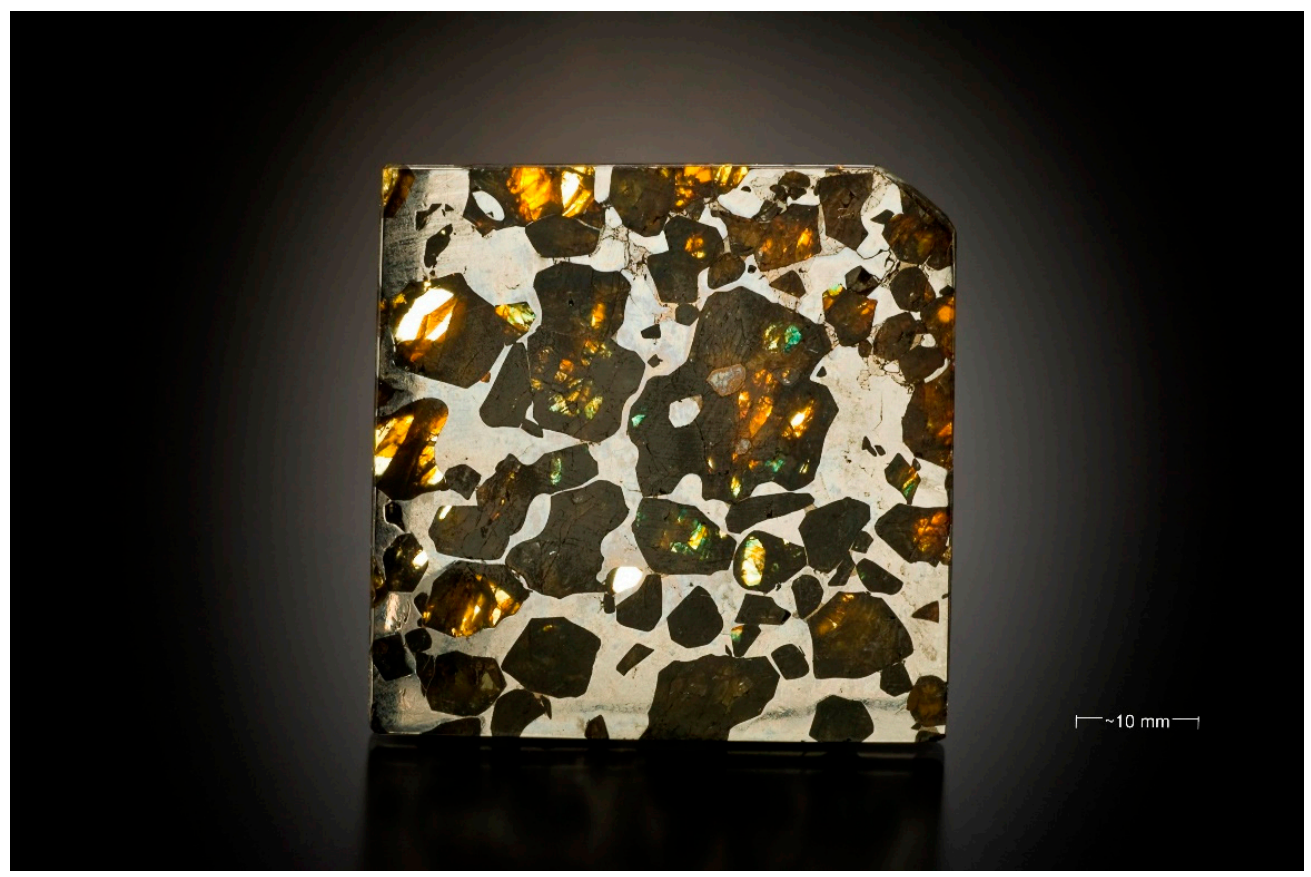

Figure 16. This is a slice of the Seymchan pallasitic meteorite $(48.00 \times 48.00 \times 2.70 \mathrm{~mm})$ from the Magadan Oblast and is illuminated by both incident and transmitted light. The light-gray areas are incident light reflected by polished iron-nickel metal, while the darker irregular areas, which we call windows, are illuminated by light originating from behind and are dominantly olivine. Although several windows can be seen here to have blue areas, the photomicrograph in Figure 17 is one of the best individual examples. Photo: Jeffrey A. Scovil; specimen from the collection of Elise A. Skalwold. 


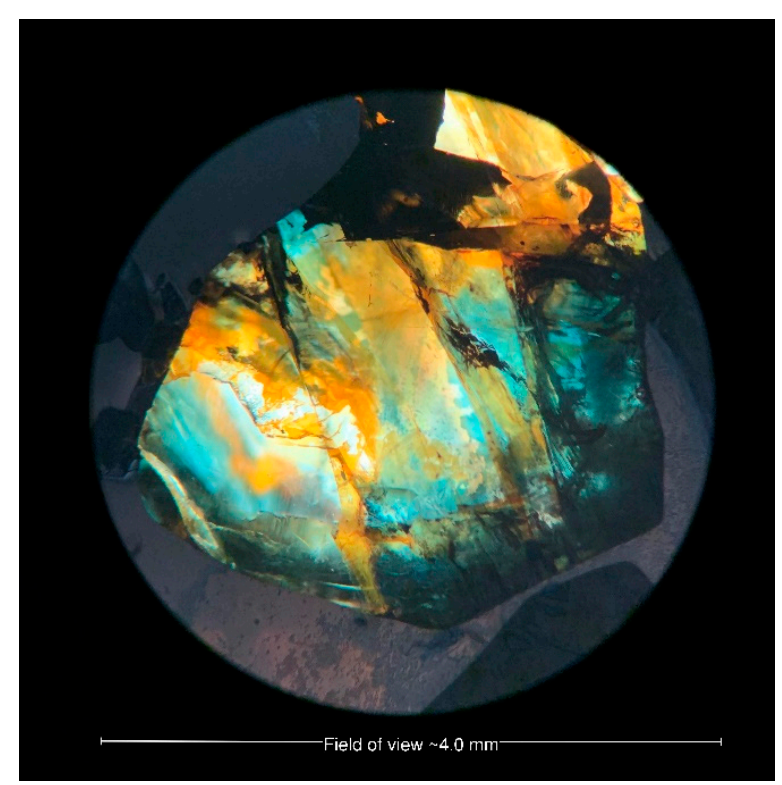

Figure 17. Blue areas in one of the olivine windows in the Seymchan pallasitic meteorite from the Magadan Oblast, Russia. The blue color ranges from light in the central area to more intense in the area to the right of center. Note the similarity to the ringwoodite in Catherwood Meteorite Figure 15. An even deeper blue can be observed in some of the smaller areas. The orange areas are almost certainly iron oxides, whereas we suggest that the blue color may be caused by iron in sites resulting from cation disorder in olivine derived from ringwoodite. Photomicrograph: Elise A. Skalwold; field of view is approximately $4.0 \mathrm{~mm}$.

To the best of our knowledge, the blue areas in this pallasite have not been definitively identified to date. They could be another example of ringwoodite-bearing meteorite or they could be blue olivine with residual disordered cations. As previously discussed in Section 5, Sequence of step 1 and step 2 transition, the displacive reordering of the oxygen atoms must precede the diffusion of the cations to the "proper" sites in the new phase. Otherwise, the cations would have no way to "know" where the cation sites are for the new phase, in this case the olivine structure. The one thing that meteorites may have in common with the blue olivine inclusion is the two-step mechanism involved in the olivine $\rightarrow$ ringwoodite or ringwoodite $\rightarrow>$ olivine phase transition. The oxygen restacking (step 1) and diffusion of cations due to high temperature (step 2) is caused by impact of the meteorites when they collided with Earth's surface or when they collided with other solar-system objects before arriving on Earth. That explanation for the blue inclusion in diamond (Figure 12) may seem counterintuitive because of unexpected shear stress inside of a diamond. However, the anisotropy of the forming olivine as a result of step 1 displacive restacking of oxygen layers from ringwoodite (ccp) to the olivine (hcp) resulting during the protracted cooling during the phase transition (Figure 13) might very well have induced shear stress at temperatures too low or too short for the diffusion required by step 2 and, therefore, retains the olivine structure resulting from step 1.

\section{Conclusions}

Using the diamond anvil cell with synchrotron radiation and visual observation on several silicates with the olivine $(\alpha)$ structure, we were able to show that shear deformation can promote the olivine-ringwoodite $(\alpha-\gamma)$ transition at temperatures $100{ }^{\circ} \mathrm{C}$ to $200{ }^{\circ} \mathrm{C}$ below the $\alpha-\gamma$ transition observed in the absence of shear deformation. In all cases, the complete transition involves a 2-step process, the first step being displacive shift of adjacent oxygen layers over each other. The second step requires diffusive migration of cations into cation sites of the new phase. Visual observations of the samples in a diamond anvil cell showed that an annular area of sample occurs, where shear deformation, pressure, and 
temperature are all sufficiently high, to promote step 1. The central area where pressure is even greater retains the $\alpha$ structure of olivine, illustrating the important role of shear deformation. The outer portion of sample near the edges retains the $\alpha$ structure due to inadequate pressure, even though shear deformation is greatest there. We suggest that the two-step transition plays an important role in water retention of ringwoodite and wadsleyite, deep-focus earthquakes, and the unusual occurrence of blue olivine.

We also suggest that the reverse transition, i.e., from $\gamma$ to $\alpha$, may account for the rare observations of blue olivine even in the presence of low shear strain as the displacive reordering of the oxygen atoms (step 1) must precede the diffusion of cations (step 2) to the sites of the new phase $(\alpha)$; otherwise, the cations would have no guidance to the sites of the new phase. The enigmatic blue olivine inclusion in a diamond which so captured our fascination may have had such an origin. Examples of two meteorites containing blue ringwoodite and a pallasite meteorite also containing blue regions that may be ringwoodite or blue olivine are described.

Author Contributions: Conceptualization, W.A.B and E.A.S.; methodology W.A.B.; formal analysis, W.A.B. and E.A.S.; investigation, W.A.B. and E.A.S.; writing-original draft preparation, W.A.B. and E.A.S.; writing-review and editing, W.A.B. and E.A.S. All authors have read and agreed to the published version of the manuscript.

Funding: This research received no external funding.

Institutional Review Board Statement: Not applicable.

Informed Consent Statement: Not applicable.

Acknowledgments: The authors are very grateful to John I. Koivula for bringing to our attention the natural diamond with its blue olivine inclusion. We want to thank Steven D. Jacobsen for his many ideas and contributions to the research devoted to the use of synchrotron radiation, as well as conventional X-ray diffraction and Raman spectroscopy, to the study of that blue inclusion. We are also very grateful for the support we received from Brookhaven beamline scientist Zhenxian Liu and Argonne Lab beamline scientists Robert Gordon, Ercan Alp, and Mark Rivers for their valuable support setting up experiments and helping to interpret results. We also greatly appreciate the encouragement by Jean Paul Poirier at the very beginning of the study. One of us, Bill, spent a few months at the University of Paris collaborating with Jean Paul Poirier on potentially interesting aspects of the olivine-ringwoodite phase transition and other high-pressure high-temperature research.

Conflicts of Interest: The authors declare no conflict of interest.

\section{References}

1. Poirier, J.P. Martensitic. Olivine-spinel transformation and plasticity of the mantle transition zone. In Anelastic Properties and Related Processes in the Earth's Mantle; Stacey, F.D., Paterson, S.M., Nicolas, A., Eds.; American Geophysical Union Monograph, AGU: Washington, DC, USA, 1981; pp. 113-117.

2. Furnish, M.D.; Bassett, W.A. Investigation of the mechanism of the olivine-spinel transition in fayalite by synchrotron radiation. J. Geophys. Res. 1983, 88, 10333-10341. [CrossRef]

3. Bassett, W.A.; Shen, A.H.; Bucknum, M.; Chou, I.-M. A new diamond anvil cell for hydrothermal studies to 2.5 GPa and from -190 to $1200{ }^{\circ}$ C. Rev. Sci. Instrum. 1993, 64, 2340-2345. [CrossRef]

4. Bassett, W.A.; Ming, L.C. Disproportionation of $\mathrm{Fe}_{2} \mathrm{SiO}_{4}$ to $\mathrm{FeO}+\mathrm{SiO}_{2}$ at pressures up to 250 kilobars and temperatures up to $3000^{\circ}$ C. Phys. Earth Planet. Int. 1972, 6, 154-160. [CrossRef]

5. Burnley, P.C.; Green, H.W. Stress dependence of the mechanism of the olivine-spinel transformation. Nature 1989, 338, 753-755. [CrossRef]

6. Burnley, P.C.; Green, H.W.; Prior, D.J. Faulting associated with the olivine to spinel transformation in $\mathrm{Mg}_{2} \mathrm{GeO}_{4}$ and its implication for deep-focus earthquakes. J. Geophys. Res. 1991, 96, 425-443. [CrossRef]

7. Wu, T.-C.; Bassett, W.A.; Burnley, P.C.; Weathers, M.S. Shear-promoted phase transitions in $\mathrm{Fe}_{2} \mathrm{SiO}_{4}$ and $\mathrm{Mg}_{2} \mathrm{SiO}_{4}$ and the mechanism of deep earthquakes. J. Geophys. Res. 1993, 98, 19767-19776. [CrossRef]

8. Burnley, P.C.; Bassett, W.A.; Wu, T.-C. Diamond anvil cell study of the transformation mechanism from olivine to spinel phase in $\mathrm{Co}_{2} \mathrm{SiO}_{4}, \mathrm{Ni}_{2} \mathrm{SiO}_{4}$, and $\mathrm{Mg}_{2} \mathrm{SiO}_{4}$, J. Geophys. Res. 1995, 100, 17715-17723. [CrossRef]

9. Suito, K. Phase relations of pure $\mathrm{Mg}_{2} \mathrm{SiO}_{4}$ up to 200 kilobars. In High-Pressure Research: Application in Geophysics; Manghnani, M.H., Akimoto, S., Eds.; Academic Press: New York, NY, USA, 1977; pp. 255-266.

10. Ito, E.; Okayama University, Misasa, Japan. Personal communication, 1991. 
11. Burnley, P.C. The effect of non-hydrostatic stress on the olivine-spinel transformation in $\mathrm{Mg}_{2} \mathrm{GeO}_{4}$. Ph.D. Thesis, University of California at Davis, Davis, CA, USA, 1990.

12. Rubie, D.C.; Bayerisches Geoinstitut, University of Bayreuth, Bayreuth, Germany. Personal communication, 1994.

13. Ringwood, A.E. Olivine-spinel transformation in cobalt orthosilicate. Nature 1963, 198, 79-80. [CrossRef]

14. Akimoto, S. High-pressure synthesis of a "modified" spinel and some geophysical implications Phys. Earth Planet Int. 1970, 3, 189-195. [CrossRef]

15. Ringwood, A.E. The constitution of the mantle 1. Thermodynamics of the olivine-spinel transition. Geochim. Cosmochim. Acta 1958, 13, 303-321.

16. Yagi, T.M.; University of Tokyo, Tokyo, Japan. Personal communication, 1991.

17. Tomioka, N.; Okuchi, T. A new high-pressure form of $\mathrm{Mg}_{2} \mathrm{SiO}_{4}$ highlighting diffusionless phase transitions of olivine. Sci. Rep. 2017, 7, 17351. [CrossRef] [PubMed]

18. Ma, C.; Tchauner, O.; Beckett, J.R.; Liu, Y.; Rossman, G.R.; Sinogeikin, S.V.; Smith, J.S.; Taylor, L.A. Ahrensite, $\gamma$-Fe $\mathrm{AiO}_{4}$, a new shock-metamorphic mineral from the Tissint meteorite: Implications for the Tissint shock event on Mars. Geochimica et Cosmochimica Acta 2016, 184, 240-256. [CrossRef]

19. Bindi, L.; Brenker, F.E.; Nestola, F.; Koch, T.E.; Prior, D.J.; Lilly, K.; Krot, A.N.; Bizzarro, M.; Xie, X. Discovery of asimowite, the Fe-analog of wadsleyite, in shock-melted silicate droplets of the Suizhou L6 and the Quebrada Chimborazo 001 CB3.0 chondrites. Am. Mineral. 2019, 4, 775-778. [CrossRef]

20. Poirier, J.P. Introduction to the Physics of the Earth's Interior, 2nd ed.; Cambridge University Press (Virtual Publishing): New York, NY, USA, 2000; pp. 251-255.

21. Kohlstedt, D.; Keppler, H.; Rubie, D. Solubility of water in the $\alpha, \beta$ and $\gamma$ phases of $(\mathrm{Mg}, \mathrm{Fe})_{2} \mathrm{SiO}_{4}$. Contrib. Miner. Petrol. 1996, 123, 345-357. [CrossRef]

22. Smyth, J.R.; Holl, C.M.; Frost, D.J.; Jacobsen, S.D.; Langenhorst, F.; McCammon, C.A. Structural systematics of hydrous ringwoodite and water in the Earth's interior. Am. Mineral. 2003, 88, 1402-1407. [CrossRef]

23. Jacobsen, S.; van Lee, S. (Eds.) Earth's Deep Water Cycle; American Geophysical Union: Washington, DC, USA, 2006; 313p, ISBN 978-875-90433-7.

24. Pearson, D.G.; Brenker, F.E.; Nestola, F.; McNeill, J.; Nasdala, L.; Hutchison, M.T.; Matveev, S.; Mather, K.; Silversmit, G.; Schmitz, S.; et al. Hydrous mantle transition zone indicated by ringwoodite included within diamond. Nature 2014, 507, 221-224. [CrossRef] [PubMed]

25. Liu, X.; Sui, Z.; Fei, H.; Yan, W.; Ma, W.Y.; Ye, Y. Cation Disorder IR Features of Hydrous $\mathrm{Mg}_{2} \mathrm{SiO}_{4}$-Ringwoodite, Unannealed and Annealed at $200-600{ }^{\circ} \mathrm{C}$ and $1 \mathrm{~atm}$, with Implications to Hydrogen Defects and Water-Coupled Cation Disorder. Minerals 2020, 10, 499. [CrossRef]

26. Koivula, J.I. The MicroWorld of Diamonds; GemWorld International, Inc.: Northbrook, IL, USA, 2000; p. 53.

27. Jacobsen, S.D.; Bassett, W.A.; Skalwold, E.A.; Koivula, J.I. Message in a bottle: Secrets from the deep Earth in a diamond inclusion. In Proceedings of the 2012 Packard Fellows Meeting, David and Lucile Packard Foundation, Monterey, CA, USA, 5-8 September 2012. funding provided by the Fellowship for Science and Engineering by the David and Lucile Packard Foundation.

28. Jacobsen, S.D.; Northwestern University, Evanston, IL, USA. Personal communication, 2020.

29. Coleman, L.C. Ringwoodite and majorite in the Catherwood meteorite. Can. Mineral. 1977, 15, 97-101.

30. Binns, R.A.; Davis, R.J.; Reed, S.J.B. Ringwoodite, Natural $\mathrm{Mg}_{2} \mathrm{SiO}_{4}$ spinel in the Tenham meteorite. Nature 1969, $221,943-944$. [CrossRef]

31. Putnis, A.; Price, G.D. High-pressure $\mathrm{Mg}_{2} \mathrm{SiO}_{4}$ phases in the Tenham chondrite meteorite. Nature 1979, 280, 217-218. [CrossRef] 